\title{
CONSTRUCCIÓN Y ORGANIZACIÓN DE UN ESPACIO LACUSTRE, LA CUENCA Y EL LAGO LLANQUIHUE EN EL SUR DE CHILE
}

\author{
Claudia Castillo Haeger \\ Centro de Desarrollo Urbano Sustentable. Universidad Católica de Chile \\ ccastilloe@uc.cl \\ Mario del Castillo Oyarzún \\ Universidad Diego Portales. Santiago de Chile. \\ mario.delcastillo@mail.udp.cl
}

\section{RESUMEN}

El Espacio Lacustre es una construcción socio temporal en un ecosistema acotado. El Llanquihue al sur de Chile es un caso singular: extenso lago de origen glaciar, cuenca asociada a dos volcanes activos, un solo desagüe natural. Reúne distintas administraciones y ciudades en su orilla, herederas de una colonización alemana en un extraordinario paisaje. El territorio habitado presenta diversos conflictos y en relación a ello se diseñan matrices de análisis y se elaboran cartografías temporales de las dimensiones ecológicas, antropológicas, económicas y de gobernanza. Los resultados promueven un modelo transversal de construcción social y ordenación sostenible del territorio bajo el concepto de Espacio Lacustre.

Palabras clave: Espacio Lacustre, Ordenación Territorial, Urbanismo Sostenible, Manejo de Cuencas.

\section{ABSTRACT}

The Lakeside Space is a temporary social construction in a limited ecosystem. Lake Llanquihue is a singular case: a lake with a glacial origin in a basin associated to two active volcanoes and both sharing only one natural drainage. It gathers different administrations and cities to its shores, heirs of a late German colonization in an extraordinary landscape. The inhabited territory presents diverse conflicts and in connection therewith, matrices of

Fecha de recepción: marzo 2015.

Fecha de aceptación: diciembre 2015. 
analysis are designed and temporal mapping of ecological, anthropological, economic and governance dimensions are elaborated. The results promote a cross model of social construction and sustainable land under the concept of the Lakeside Space.

Keywords: Lakeside Basin Space, Spatial Planning, Sustainable Urbanism, Watershed Management.

\section{UNA DEFINICIÓN DEL ESPACIO LACUSTRE}

El paradigma de la sostenibilidad, la carencia de recursos, el conocimiento de la huella ecológica o la pérdida de la biodiversidad ambiental nos obligan a analizar los territorios de una manera multidimensional para ser capaces de prever o solucionar los distintos problemas o competencias que en ellos se producen. De tal modo reconocemos el Espacio Lacustre como un espacio único y de especial vulnerabilidad e interés que describe unos determinados valores culturales, históricos, paisajísticos; un espacio acotado y frágil en el que los aspectos de interrelación y/o interdependencia de los usos y las actividades que soporta, resultan clave al estar conectadas y comprometidas su capacidad, calidad e integridad.

Un lago por sí solo no forma Espacio Lacustre; tampoco lo hace la ribera o la cuenca hidrográfica por separado. Es la construcción socio temporal y la percepción del espacio común, sumado al uso y la acción sobre este territorio específico, lo que integra esta espacialidad única, interdependiente, finita y determinada (Folch, 2003). Es una categoría distinta a la litoral, a las cuencas fluviales o al espacio rural; es un espacio que estructura unas dimensiones dependientes entre sí (Castillo, 2010). Hoy el Espacio Lacustre se encuentra modificado por la actividad del hombre, la agricultura intensiva, el turismo estacional o la ocupación industrial del suelo; hay nuevos requerimientos espaciales que no están siendo visualizados, con propiedades de interacción complejas, sistémicas y que involucran todos los recursos de un Espacio Lacustre.

El Espacio Lacustre es una construcción socio temporal que se desarrolla en un ecosistema acotado: un territorio frágil y trascendente, donde los cambios producidos por la acción del hombre reflejan la cultura de la sociedad que lo habita. Parece adecuado organizar una escala territorial de cuenca, con la integración efectiva de los procesos hidrológicos y ecológicos, así como las realidades sociales y actividades económicas de las comunidades residentes, trascendiendo el marco legal disperso y las divisiones administrativas específicas. El Espacio Lacustre como patrimonio ambiental, social y económico es un paisaje natural y cultural que resulta enriquecido por la huella histórica de la acción humana (Zoido, 2000), el desarrollo de las sociedades lacustres y por la presencia de las ciudades y construcciones ubicadas en su territorio de cuenca.

El Espacio Lacustre se presenta: polisémico, con diferentes significados sociales, históricos, culturales, de tradición e identidad. multiescalar, con usos superpuestos en diferentes intensidades y a distintas escalas de acción sobre el Espacio Lacustre. polifuncional en las diversas actividades económicas que soporta, atemporal y sincrónico, ya que si bien el Espacio Lacustre se transforma en el tiempo, sigue permaneciendo como integración y relación de las cuatro dimensiones que lo conforman (Fig.01). 
La dimensión ecológica del Espacio Lacustre se reconoce y desarrolla a través de una matriz biofísica del territorio, desde la hidrosfera viva estudiando el camino del agua al lago; plantea las riberas lacustres como una interface necesaria para esta matriz, elabora un acercamiento a la cuenca lacustre entendiendo la litosfera cóncava como una unidad paisajística de patrones acotados e interrelacionados para concluir con el análisis integral del Espacio Lacustre como un gran ecosistema (WRI 2005). Al mismo tiempo, es la construcción social del Espacio Lacustre la que nos conduce a la dimensión antropológica y se constituye como una matriz que relaciona y expresa elementos como la cultura, la historia, o el paisaje cultural; reconoce una impronta social particular con derechos adquiridos con una manera propia de ocupar un territorio específico, urbano y rural (Rees, 1996).

La matriz biofísica que conforma el Espacio Lacustre relaciona a la vez los cuatro elementos siguientes: Agua y lago. Ribera lacustre. Cuenca Hidrográfica. Ecosistema. El Espacio Lacustre a través de su Dimensión Ecológica comprende un gran ecosistema junto a la biodiversidad del cuerpo de agua, de la cuenca hidrográfica lacustre en particular y de la ribera u orilla como una zona de transición entre la litosfera terrestre y la hidrosfera del lago. En cuanto a las características podemos decir que:

- Un gran ecosistema con jerarquías, escalas y dependencias: lago ribera y cuenca.

- La fragilidad lacustre, equilibrio del ciclo, temporalidad, resiliencia e integridad.

- Su hidrología, dinamismo del agua, tasas de renovación, cauces y aguas subterráneas.

- El capital natural, bienes naturales protegidos, biodiversidad y su distribución.

El Espacio Lacustre estructura las dimensiones antropológicas a través de una matriz social única, como un capital social particular, una expresión de la estructura histórica, cultural, paisajística, con derechos adquiridos en una manera de ocupar el territorio específica, urbana o rural. Es la construcción social del Espacio Lacustre la que nos conduce a la dimensión antropológica del mismo, y se constituye como una matriz social que relaciona los siguientes elementos: Cultura. Derechos. Paisajes. Urbano y Rural.

La dimensión antropológica del Espacio Lacustre se determina a través de los distintos usos que el hombre le ha dado a lo largo de la historia; con una densidad demográfica y ocupación determinada, con un paisaje particular, natural y construido, con una historia, tradiciones y cultura específicas, con un uso urbano y rural de la misma cuenca y con una manera pública o privada característica que ha tenido el aprovechamiento de este espacio. Ahora sintetizando la dimensión antropológica, podemos decir que la matriz social del Espacio Lacustre se encuentra caracterizada por:

- El capital social, cultura, demografía, educación, salud, tradiciones y simbolismos.

- Los derechos, bienes de uso público, derechos individuales y colectivos de aguas y tierras.

- El paisaje en un territorio acotado, patrones y unidades de materiales y de energía.

- Su ocupación, densidades, sistemas de agrupación o dispersión, división del suelo.

En la dimensión económica se explica el elevado número de actividades y usos que sostiene el Espacio Lacustre como su principal característica y se describen las acciones 
conflictivas en el lago, la ribera, la cuenca y el ecosistema; se señalan características cíclicas, la complejidad y la interdependencia en el Espacio Lacustre; las competencias, la intensidad de las presiones económicas y la resolución (o no) de los conflictos ambientales en la disputa por un mismo espacio, reconociendo los problemas actuales del desarrollo, la degradación ambiental o la globalización económica (Naredo, 2006).

La dimensión económica del Espacio Lacustre se destaca en el desarrollo de actividades extractivas o primarias (pesca, minería, forestal o canteras), productivas, secundarias o industriales (energía, acuicultura, silvicultura, ganadería o agricultura), terciarias (de ocio, recreación, servicios, turismo, comercio o deporte) y algunas con carácter conectivo, es decir los ejes y las distintas redes de comunicación. El Espacio Lacustre es un espacio complejo y singular por la articulación de factores que deben ser estudiados para establecer la regulación y control sobre el uso del agua y del suelo para asumir estrategias de sostenibilidad en el desarrollo y la localización de las actividades humanas dentro de un sistema. Concretando, el Espacio Lacustre estructura una dimensión económica, a través de una matriz de las distintas actividades en él desarrolladas: Extractivas: pesca, minería, forestal, canteras. Productivas: energía, acuicultura, silvicultura, ganadería, agricultura. Terciarias: servicios, comercio, deportes, turismo. Urbanización: ciudades, conectividad, redes, transportes.

Esta dimensión económica del Espacio Lacustre se determina a través de las siguientes características:

- La Intensidad de las actividades económicas y su nivel de desarrollo, cargas e impactos.

- El capital económico, economía ecológica, economías locales y los servicios ambientales.

- La compatibilidad, mono o multifunción, conflictos o disputas por los bienes ambientales.

- Su estructura urbana, jerarquía de ciudades y de redes, conectividad multimodal.

Finalmente se reconoce una dimensión de gobernanza como la que intermedia entre las dimensiones Ecológica, Antropológica y Económica del Espacio Lacustre, estableciendo límites y administrando los bienes naturales entre los usos y actividades permitidos, en jerarquía y coordinación con el resto del sistema legal y administrativo (Dourejeanni, Jouravlev, 2001). En el Espacio Lacustre esta Dimensión de Gobernanza se constituye a través de una matriz de regulación política y de los distintos modos de organización presentes, relacionando la participación, el gobierno, las instituciones, los acuerdos, las normas o las leyes, entre otros.

La dimensión de gobernanza intermedia entre las dimensiones ecológica, antropológica y económica, establece limitaciones y administra los bienes naturales, unidades ambientales, entre usos y actividades económicas y jerarquía y coordinación con el resto del sistema legal y administrativo. En el Espacio Lacustre la dimensión de gobernanza se constituye a través de una matriz de regulación política y de los distintos modos de organización que lo afectan relacionando los siguientes elementos: Participación base. Instituciones y gobierno. Convenios y acuerdos. Instrumentos y leyes.

Esta dimensión se determina a través de las siguientes características:

- El sistema político imperante, de gobierno, la financiación y sus políticas y programas.

- La administración, las competencias de instituciones y de organismos presentes. 
- Su legislación, los instrumentos, planes, leyes y reglamentos, su seguimiento y control.

- La autorregulación, la base de participación, los métodos, convenios y acuerdos.

Figura 1

DIMENSIONES Y ELEMENTOS DEL ESPACIO LACUSTRE

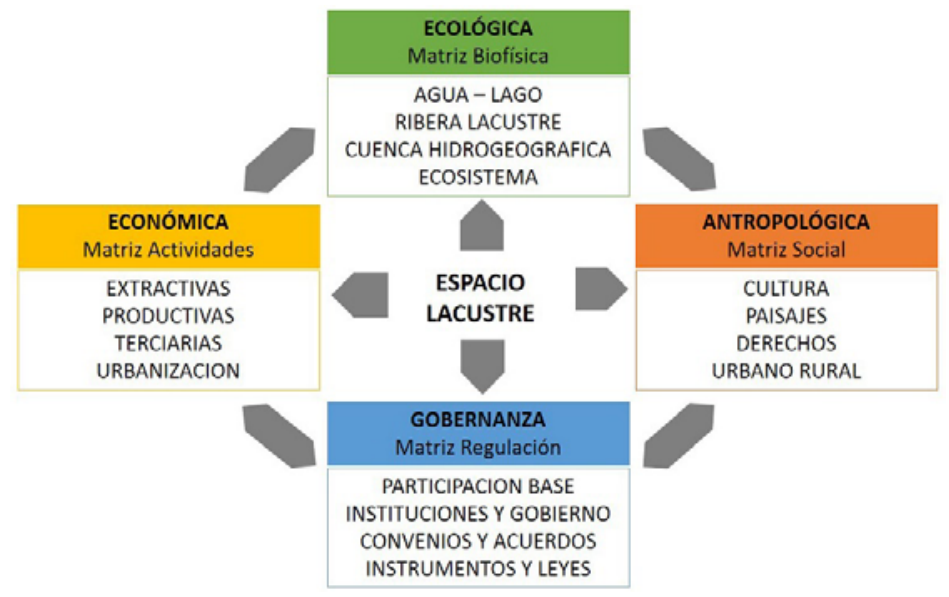

Fuente: elaboración propia en base a La Organización del Espacio Lacustre, desde la superación del planeamiento sectorial (Castillo, 2010).

\section{ANTECEDENTES}

El Espacio Lacustre puede encontrar algunos referentes en las ideas de Geddes, Lefebvre y Mc Harg; con la Sección del Valle, la Revolución Urbana y Proyectar con la Naturaleza, respectivamente. Estos autores plantean una interesante conceptualización espacial que se relaciona con la visión transversal del Espacio Lacustre, aunque si bien no agotan un proceso de revisión teórica; estas propuestas atemporales y precedentes sirven de marco teórico para la investigación ya que destacan en sus aproximaciones particulares a las dimensiones no evidentes y complementarias a un Espacio Lacustre. El objetivo entonces es destacar las pautas de análisis, de relación y de aproximación al territorio urbano y rural considerando las distintas dimensiones que ellos plantean.

La Sección del Valle (Geddes, 1973) nos presenta una transformación del espacio por el trabajo económico de sus habitantes, en una linealidad territorial que bien podría ser un ciclo hidrológico de la montaña al mar, en primer orden la dimensión ecológica y económica se encuentran muy relacionadas y se establecen sus dependencias directas. En segundo orden preocupa la dimensión antropológica y específicamente la relación urbana-rural de los habitantes. Finalmente la dimensión de gobernanza se encuentra menos elaborada ya que sólo menciona una sistematización de la planificación. La Sección del Valle como una visión lineal que atraviesa el territorio de la montaña al mar con unas dimensiones de interacción acotadas, nos señala las dependencias de las actividades sobre un territorio y su consecuente relación con los usos del mismo territorio, aguas abajo. Por lo tanto existe una integración 
entre hombre, naturaleza y el soporte material construido (Castillo, C. 2010). En consecuencia el ambiente es el vehículo a través del que se produce la evolución, ya que, cada mejora que hace un individuo, repercute en el siguiente y así sucesivamente.

Algunos conceptos relevantes señalados por Geddes (Volker, 2002): consideración del espacio habitable como una totalidad sistémica, integrada, que comprende tanto los espacios urbanos como los rurales en interacción; necesidad de realizar estudios multidisciplinarios previos del área territorial a ordenar; generación de directrices de planeamiento que se irán implementando día a día, mediante estudios y proyectos seccionales en los cuales participarán numerosos autores; diversificación de las respuestas; elevación de la densidad de población en medio urbano; el espacio regional como un espacio de interés también paisajístico y disfrute colectivo.

En el caso de La Revolución Urbana (Lefebvre, 1970) el énfasis supone un concepto más bien sociológico: la construcción social del territorio relacionando al trabajo y a la urbanización desde lo rural hasta lo urbano, evidenciando el problema de las nuevas dimensiones de lo urbano sobre un territorio común. El urbanismo asume y tiene también un carácter social, sirve a intereses de grupos y personas, satisface ciertas necesidades específicas. Lefebvre considera que la problemática urbana es mundial (Garnier, 1976). Además, los mismos problemas se manifiestan tanto en el socialismo como en el capitalismo (Lindón, 2003). La sociedad urbana es una sociedad planetaria, que ocupa el planeta recreando la naturaleza, borrada por la explotación industrial y la destrucción de los recursos naturales. Lefebvre, ha sido uno de los primeros en poner en evidencia el hecho de que el urbanismo como ideología formula todos los problemas de la sociedad en cuestiones de espacio y traslada a términos espaciales todo aquello que viene de la historia (Castell, 1998).

Así entonces, La Revolución Urbana no es una traducción directa de la globalización en el territorio, pero sí que viene causada por un conjunto de factores tecnológicos, económicos, políticos, sociales y culturales que también se vinculan a la globalización; concepto por otra parte suficientemente confuso lo que permite que sirva un poco para todo. Como se ha comentado, la difusión del fenómeno urbano al espacio rural no se ha producido a través de unos planteamientos racionales que generen una estructura territorial ordenada, sino, todo lo contrario, la improvisación, la irregularidad, el desorden y, en última instancia, el fracaso del urbanismo ha sido lo imperante. La falta de control sobre las implantaciones ha sido total en la mayoría de los casos, llegando a constituir su existencia desorganizada una de las principales causas de la desarticulación territorial de muchos municipios.

Finalmente Proyectar con la Naturaleza (Mc Harg, 1969), se centra en la dimensión ecológica del Espacio Lacustre como base de un planteamiento territorial al considerar el carácter integrador de la naturaleza como el rasgo primordial de la metodología de la planificación ecológica. En segundo lugar considera la dimensión económica al decir que tenemos un único modelo explícito del mundo y éste está basado en la economía, el determinismo económico como una forma de evaluación imperfecta del mundo biofísico es sólo una de las consecuencias de nuestro legado. Por último las dimensiones antropológica y de gobernanza ya que relaciona tanto la metodología de mapeo como la necesidad de cartografiar la matriz social. No obstante, aunque su vocación sea crear espacio, no se alcanza a constituir realmente quedándose en la especificidad de los trabajos de superposición de mapas temáticos tanto ecológicos como económicos adelantándose de esta manera a los sistemas de información geográfica contemporáneos (Verdaguer, 2002). 


\section{CUENCA Y LAGO LLANQUIHUE, CHILE}

Volviendo ahora la atención al caso de estudio, y reconociendo en primer lugar que dadas las peculiares características de las cuencas lacustres de origen glaciar, donde la intensidad y diversidad de los usos y actividades en el Espacio Lacustre comprometen el espacio mismo (los patrones de paisajes, el lago, la cuenca, el territorio y su biodiversidad), se ha pensado en la importancia de estudiar el estado actual de su organización teniendo en cuenta el papel creciente de los espacios naturales significativos (y frágiles como el Espacio Lacustre) en los acelerados procesos de urbanización.: ¿De qué manera se relacionan (o no) las planificaciones sectoriales? ¿De qué manera intervienen o compiten dada la confluencia de intereses, usos y actividades que en todo orden reúne el Espacio Lacustre? ¿Es posible una organización del Espacio Lacustre, desde la superación del planeamiento sectorial?

El Espacio Lacustre de la cuenca y el lago Llanquihue al sur de Chile, nos brinda la oportunidad de comprender una complejidad única, una evidencia de la alteración del equilibrio sistémico de entradas y salidas, una dimensión ecológica con una rica matriz biofísica, una dimensión antropológica única con el legado de la colonización alemana de mediados de s. XIX, sumado a una dimensión económica emergente y que presiona a la dimensión de gobernanza joven, sectorial y dispersa, con vacíos y superposiciones evidentes en el planeamiento del Espacio Lacustre. (Fig. 02 y 03).

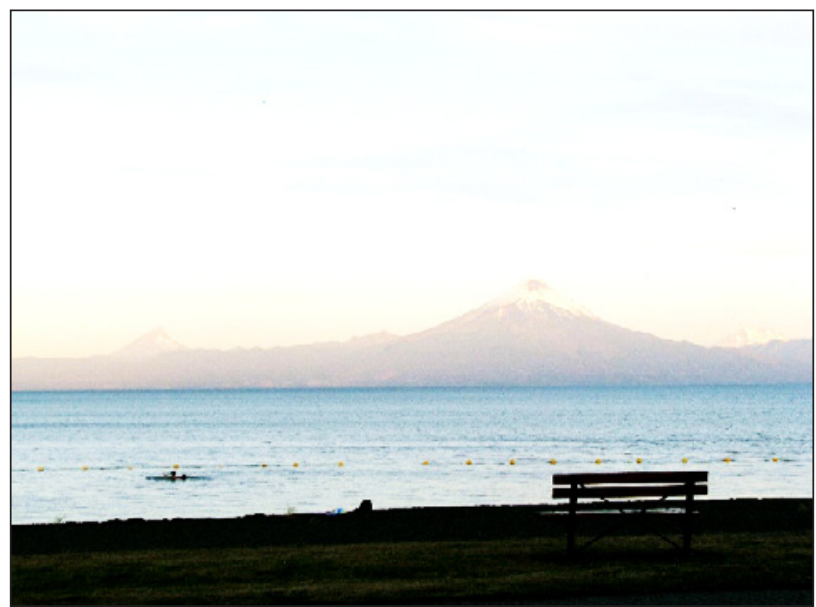

Fuente: Archivo personal, Mario Del Castillo 2006.

El caso del Llanquihue es singular, un lago de origen glaciar de $860 \mathrm{~km}^{2}$ de lámina de agua, con una cuenca de $4000 \mathrm{~km}^{2}$ asociada a dos volcanes activos (Osorno y Calbuco) y con un único desagüe natural en el río Maullín (CEC, 2007). Reúne administraciones distintas y diferentes ciudades en su orilla, herederas de una colonización alemana tardía en un entorno 
ambiental de calidad inserto en un extraordinario paisaje. El territorio habitado presenta conflictos emergentes: el aumento de densidades demográficas y de urbanización (turística, residencial, industrial), una acelerada intensidad de actividades y usos (agrícolas, ganaderas, acuícolas, forestales) con impactos relevantes y un mayor tráfico multimodal (agua, aire y tierra), en un marco legal de protección ambiental (en el área volcánica y silvestre protegida) (Chileambiente, 2005).

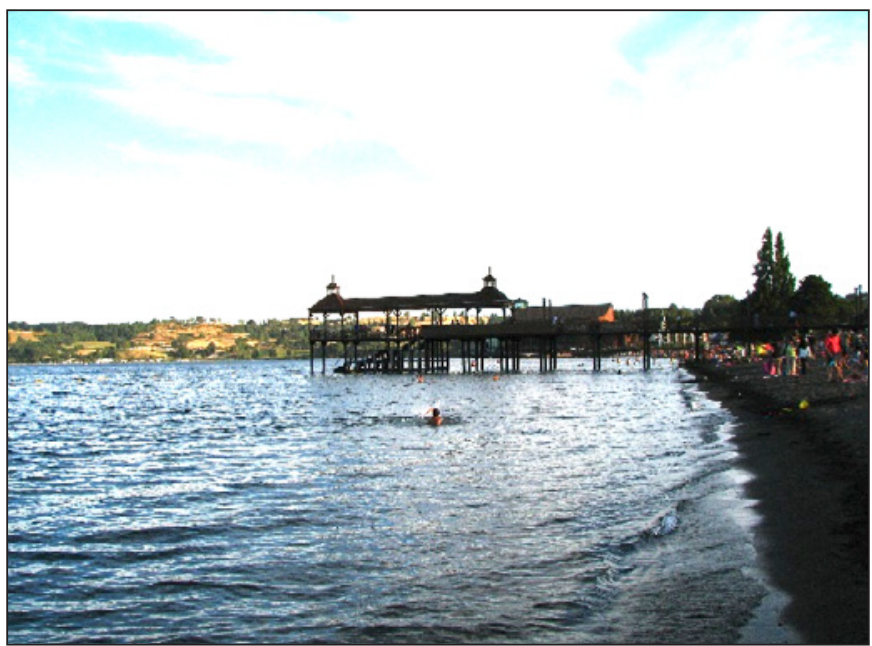

Fuente: Archivo personal, Mario Del Castillo 2006.

En la construcción social de este Espacio Lacustre característico, se comprende cómo desde el descubrimiento y posterior colonización por parte de los inmigrantes alemanes de mediados del S.XIX, este espacio ha sido el núcleo del desarrollo de una rica cultura e historia particular de ocupación urbana y rural de la cuenca - ribera - lago, transformando a través del poblamiento su espacio en un paisaje cultural y productivo característico (Fariña e Higueras, 1999).

El momento económico que vive Chile presenta indicadores macro que satisfacen las expectativas de inversores y prestamistas globales. Sin embargo, en este análisis optimista no se toma en cuenta el impacto que un desarrollo acelerado puede tener sobre el ambiente, el propio territorio y la calidad de vida de sus habitantes (Del Castillo, 2009). En la cuenca del Lago Llanquihue se ha producido un cambio considerable en el equilibrio del ciclo de materiales, de energía, de habitantes, de residuos, etc, (CONAMA 2008) producto de su importante biodiversidad, su atractivo natural y de su historia particular. Allí la interrelación de las dimensiones del Espacio Lacustre se han hecho visibles porque funcionan sobre la misma estructura de relaciones, la matriz biofísica se hace evidente en el tiempo y con el aumento de la presión (y cambios) en las matrices social y de actividades presentes (Fig.04). 


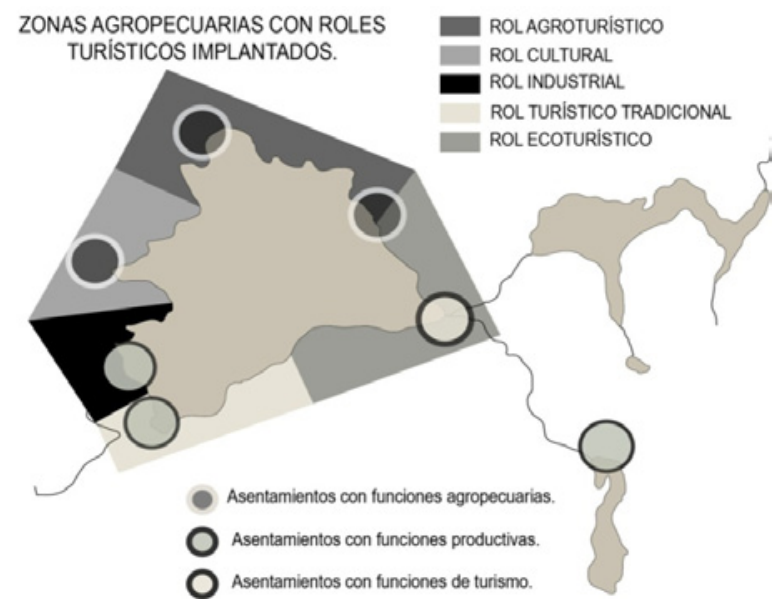

Fuente: La Organización del Espacio Lacustre, desde la superación del planeamiento sectorial (Castillo, 2010).

En la cuenca del Lago Llanquihue se ha producido un cambio considerable en el equilibrio de entradas y salidas (de materiales, de energía, de habitantes, de residuos, etc) producto de su importante biodiversidad y de su historia particular. Allí la interrelación de las dimensiones del Espacio Lacustre se han hecho visibles porque funcionan sobre la misma estructura de relaciones, la matriz biofísica se hace evidente en el tiempo y con el aumento de la presión (y cambios) en las matrices antropológica y de actividades; en cuanto a la matriz de regulación, ha sido interesante el determinar cómo los diferentes instrumentos de ordenación territorial, urbana o rural se encuentran presentes en este Espacio Lacustre sumados al planeamiento sectorial que ha respondido mayoritariamente a las actividades económicas predominantes, y se comprueba que la imprevisión del planeamiento o la inadecuada articulación de herramientas ha permitido la situación actual. En cuanto a la matriz de regulación, ha sido interesante el determinar los diferentes instrumentos de ordenación territorial, urbana o rural que se encuentran presentes en este Espacio Lacustre sumados al planeamiento sectorial productivo y terciario que ha respondido mayoritariamente a las actividades económicas predominantes, donde se comprueba que la imprevisión del planeamiento local o la inadecuada articulación de herramientas ha permitido la situación actual.

\section{MATRICES DE ANÁLISIS}

El estudio de las interdependencias del Espacio Lacustre ayuda a establecer que éste es un espacio relacional y multidimensional que se presenta descompensado o alterado, ya que la caracterización de sus relaciones depende de un contexto temporal- urbano preciso (Castillo, 2010). Se propone un modelo matricial que articule los aspectos teóricos y metodológicos planteados y que describa la interacción de las cuatro dimensiones de un Espacio 
Lacustre. Se pretende establecer el peso de las relaciones entre las dimensiones Ecológica, Antropológica, Económica y de Gobernanza, reconociendo de partida que al ser del tipo dinámicas y contextuales, no podrán en una primera aproximación ser valoradas con magnitudes o ponderaciones explícitas. En el Espacio Lacustre convergen relaciones transversales y simultáneas, es posible agruparlas para su mejor comprensión en tres ámbitos de relación ascendente: información, interacción y ordenación.

\section{IV.1. Información > Sistematización}

El Espacio Lacustre es una realidad; cultural, histórica, natural, paisajística, de actividades y de leyes sobre un territorio singular. La información de un Espacio Lacustre es particular a cada lago, se estructura y relaciona sobre sus cuatro dimensiones (Fig.05).

Figura 5

INFORMACIÓN DEL ESPACIO LACUSTRE DEL LAGO LLANQUIHUE

\begin{tabular}{|c|c|c|c|}
\hline DIMENSION & ELEMENTOS & CARACTERISTICAS & VARIABLES \\
\hline \multirow{4}{*}{$\begin{array}{l}\text { Matriz } \\
\text { biofisica }\end{array}$} & \multirow{4}{*}{$\begin{array}{l}\text {-AGUA / LAGO } \\
\text {-RIBERA LACUSTRE } \\
\text {-CUENCA } \\
\text { HIDROGRÁFICA } \\
\text {-ECOSISTEMA }\end{array}$} & 1. GRAN ECOSISTEMA & $\begin{array}{l}\text {-Jerarquia de ecosistemas } \\
\text {-Tipos de ecosistemas } \\
\text {-Relaciones y dependencias }\end{array}$ \\
\hline & & 2. FRAGILIDAD & $\begin{array}{l}\text {-Equilibrio del ciclo lacustre } \\
\text {-Impactos en el tiempo } \\
\text {-Integridad, resiliencia }\end{array}$ \\
\hline & & 3. HIDROLOGIA & $\begin{array}{l}\text {-Volúmenes de aguas, caudales. } \\
\text {-Tasa de renovación } \\
\text {-Usos y concesiones }\end{array}$ \\
\hline & & 4. CAPITAL NATURAL & $\begin{array}{l}\text {-Bienes naturales protegidos } \\
\text {-Biodiversidad } \\
\text {-Distribución }\end{array}$ \\
\hline DIMENSION & ELEMENTOS & CARACTERISTICAS & VARIABLES \\
\hline \multirow[t]{4}{*}{ ANTROPOLÓGICA } & \multirow{4}{*}{$\begin{array}{l}\text {-CULTURA } \\
\text {-PAISAJES } \\
\text {-DERECHO S } \\
\text {-URBANO Y RURAL }\end{array}$} & 5. CAPITAL SOCIAL. & $\begin{array}{l}\text {-Tradiciones y simbolismo } \\
\text {-Demografia local } \\
\text {-Educación y salud }\end{array}$ \\
\hline & & 6. DERECHOS & $\begin{array}{l}\text {-Bienes de uso público } \\
\text {-Derechos de agua y tierra } \\
\text {-Derechos individuales y colectivos }\end{array}$ \\
\hline & & 7. PAISAJES & $\begin{array}{l}\text {-Patrones } \\
\text {-Unidades de paisajes } \\
\text {-Transiciones }\end{array}$ \\
\hline & & 8. OCUPACIÓN & $\begin{array}{l}\text {-Sistema de agrupación - dispersión } \\
\text {-Densidades de ocupación } \\
\text {-División del suelo }\end{array}$ \\
\hline DIMENSION & ELEMENTOS & CARACTERISTICAS & VARIABLES \\
\hline \multirow{4}{*}{$\begin{array}{c}\text { ECONÓMICA } \\
\text { Matriz } \\
\text { actividades }\end{array}$} & \multirow{4}{*}{$\begin{array}{l}\text {-ACTIVIDADES } \\
\text { EXTRACTIVAS } \\
\text { - ACTIVIDADES } \\
\text { PRODUCTIVAS } \\
\text { - ACTIVIDADES } \\
\text { TERCIARIAS } \\
\text {-CONECTIVIDAD }\end{array}$} & 9. INTENSIDAD & $\begin{array}{l}\text { - Cantidad de actividades económicas } \\
\text { - Nivel de desarrollo } \\
\text {-Carga e impactos }\end{array}$ \\
\hline & & 10. CAPITAL ECONOMICO & $\begin{array}{l}\text {-Valoración Economia ecológica } \\
\text {-Bienes y Servicios ambientales } \\
\text {-Economias locales }\end{array}$ \\
\hline & & 11.COMPATIBILIDAD & $\begin{array}{l}\text {-Conflictos y disputas } \\
\text {-Mono o multifunción. } \\
\text {-Servicios ambientales comunes }\end{array}$ \\
\hline & & 12. COMUNICACION & $\begin{array}{l}\text {-Conectividades } \\
\text {-Evolución de sistemas de transporte } \\
\text {-Jerarquía de redes }\end{array}$ \\
\hline DIMENSION & ELEMENTOS & CARACTERISTICAS & VARIABLES \\
\hline \multirow{4}{*}{$\begin{array}{c}\text { GOBERNANZA } \\
\text { Matriz } \\
\text { regulación }\end{array}$} & \multirow{4}{*}{$\begin{array}{l}\text { - PARTICIPACIÓN } \\
\text { BASE } \\
\text { - INSTITUCIONES } \\
\text { /GOBIERNO } \\
\text { - CONVENIOS } \\
\text { NORMAS } \\
\text {-INSTRUMENTOS } \\
\text { /LEYES }\end{array}$} & 13. SISTEMA POLITICO & $\begin{array}{l}\text {-Sistemas de gobierno } \\
\text {-Financiación } \\
\text {-Politicas y programas }\end{array}$ \\
\hline & & 14.ADMINISTRACION & $\begin{array}{l}\text {-Instituciones y organismos } \\
\text {-Competencias, seguimiento y control } \\
\text {-Sistemas de propiedad }\end{array}$ \\
\hline & & 15.LEGISLACION & $\begin{array}{l}\text {-Instrumentos, planes } \\
\text {-Leyes y reglamentos } \\
\text {-Régimen del suelo }\end{array}$ \\
\hline & & 16.AUTO REGULACIÓN & $\begin{array}{l}\text {-Participación de base } \\
\text {-Métodos participativos } \\
\text {-Convenios y acuerdos }\end{array}$ \\
\hline
\end{tabular}

Fuente: La Organización del Espacio Lacustre, desde la superación del planeamiento sectorial (Castillo, 2010). 
En este primer ámbito de información se puede sistematizar la Información como una caracterización espacial y comprende un desarrollo de variables cuantitativas y cualitativas que definen este espacio singular en una propuesta de dos tablas de información. Estas tablas consideran la información de las cuatro dimensiones organizando así la simultaneidad de las características y la transversalidad de los elementos de un Espacio Lacustre con una propuesta de variables por característica que lo definen como una manera de organizar la información de la complejidad existente.

\section{IV.2. Interacción > Matrices}

El segundo ámbito de Interacción plantea una valoración de las actividades que en el Espacio Lacustre se desarrollan a modo de lente con qué mirar y comprender las interdependencias considerando en mayor medida las tres primeras dimensiones, Ecológica, Antropológica y Económica. Las relaciones más complejas se encuentran en el ámbito de la interacción y para su visualizar mejor su relación se ha diseñado tres matrices:

Matriz 1 Características= Dimensión/Dimensión

Matriz 2 Impacto= Actividad/ Dimensión

Matriz 3 Compatibilidad $=$ Actividad/Actividad

Para el caso del Espacio Lacustre del Lago Llanquihue se muestra en la Figura 06 el desarrollo de la Matriz 1 Características= Dimensión/Dimensión.

Esta primera matriz aporta un enfoque de relaciones que caracterizan el Espacio Lacustre y que se cumplen en el caso del Llanquihue. Se corresponde el hecho de que para la Dimensión Ecológica el máximo se encuentra en la característica 3.Hidrología que es el recurso hidríco más presente en el Llanquihue y el mínimo en la característica 1.Gran Ecosistema que es la limitada e indirecta percepción que se tiene de la complejidad ecosistémica del Espacio Lacustre del Llanquihue.

Para la dimensión Antropológica el máximo se encuentra en la característica 8.Ocupación siendo característico de este Espacio Lacustre su dispersión en la cuenca y la particularidad de sus ciudades, al contrario las relaciones indirectas se encuentran la característica 5. Capital Social lo que puede indicar una mayor percepción social de la forma de ocupación del territorio rural o urbano en el Espacio Lacustre por sobre la construcción social del espacio y su capital social.

Para la dimensión Económica el máximo puntaje con relaciones directas se encuentra en las características 10.Capital Económico y 12.Comunicación poniendo en relieve la variable comercial a través del flujo de capitales y los medios de comunicación, primero lacustres, luego ferroviarios y finalmente por carreteras y autovías internacionales. La menor relación directa o más relaciones indirectas para esta dimensión se encuentran en las características 9.Intensidad y 11.Compatibilidad porque ha primado la percepción cortoplacista y desarrollista de hacer negocio (monopolizando e intensificando las actividades) junto a la idea de urbanizar todo el territorio y construir caminos.

Finalmente para la dimensión de Gobernanza el máximo se encuentra en la característica 14.Administración, entendiendo que la relación directa con las autoridades locales y la inver- 
sión que se hace en pequeña escala es la que es más visible e identifica la administración elegida directamente por los habitantes. Ahora el mínimo se encuentra en la característica 15.Legislación (que coincide a su vez es el mínimo de la matriz), esto puede entenderse como una menor percepción de la legislación regulatoria en un Espacio Lacustre o simplemente al desconocimiento por superposición o vacios que generan las legislaciones sectoriales que implican al Espacio Lacustre.

Figura 6

INTERACCIÓN EN EL ESPACIO LACUSTRE DEL LAGO LLANQUIHUE. MATRIZ 1 CARACTERISTICAS= DIMENSIÓN/DIMENSIÓN

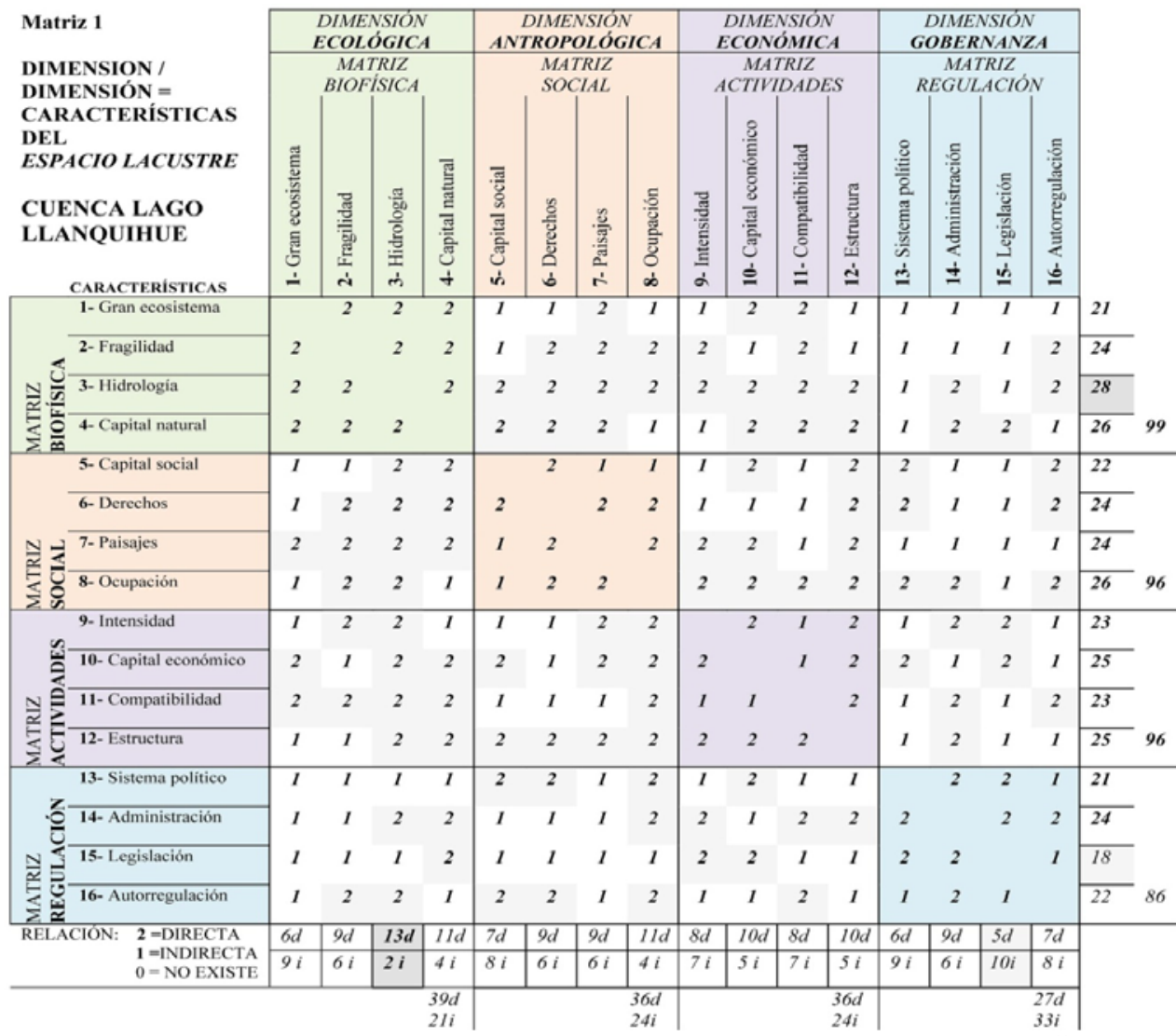

Fuente: La Organización del Espacio Lacustre, desde la superación del planeamiento sectorial (Castillo, 2010).

A raíz de esta matriz de caracterización, cabe destacar la gran importancia de la Hidrología como característica transversal de mayor valor en las sumas horizontales y a la vez con mayor cantidad de relaciones directas en relación a las demás características, prueba de ellos es el intento regulatorio a través de la norma ambiental de las aguas del lago Llanquihue y la estrategia de cuencas hidrográficas. 
Por consecuencia la relevancia de la Dimensión Ecológica por sobre las otras dimensiones del Espacio Lacustre como generadora de un mayor número de relaciones directas entre todas sus características.

\section{IV.3. Ordenación > Cuadros}

En el tercer ámbito Ordenación, se considera la cuarta dimensión del Espacio Lacustre: Gobernanza, como punto de partida del análisis y síntesis de las relaciones organizativas o de regulación existentes en un Espacio Lacustre. Se proponen dos cuadros de valoración: uno de la organización por dimensión del Espacio Lacustre y un segundo cuadro que identifica la ordenación del mismo en cuanto a la interacción de sus instrumentos. En la Fig. 07 se desarrolla el Cuadro 1 Organización del Espacio Lacustre aplicado al caso de la cuenca lacustre del Llanquihue en el sur de Chile.

Figura 7

CUADRO 1 ORGANIZACIÓN, ELEMENTOS/D. GOBERNANZA DEL ESPACIO LACUSTRE LLANQUIHUE

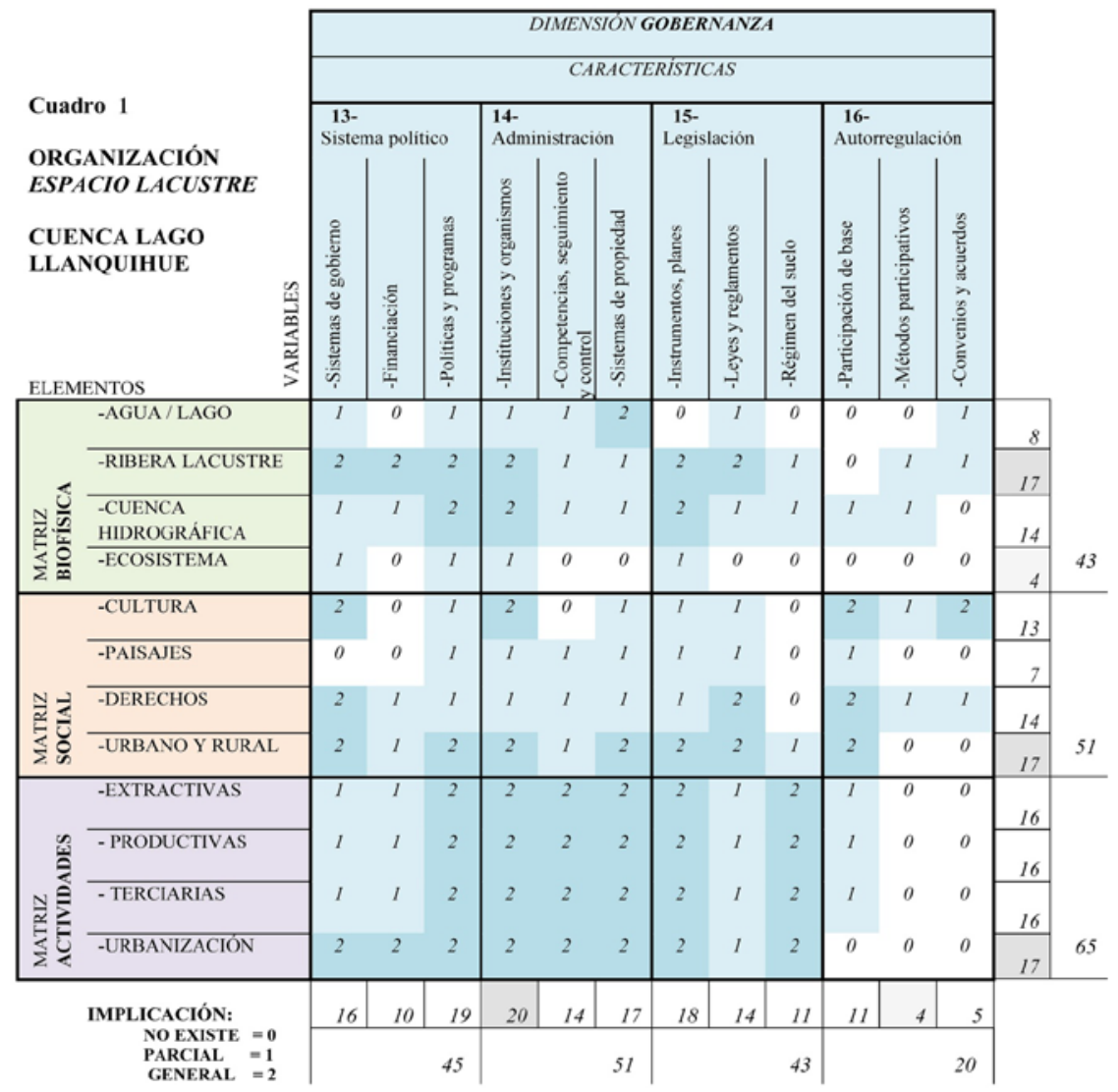

Fuente: La Organización del Espacio Lacustre, desde la superación del planeamiento sectorial (Castillo, 2010). 
Se valora en este cuadro la consideración -Parcial/Total- de los elementos del Espacio Lacustre con las cuatro características de su Dimensión de Gobernanza. En la Dimensión Ecológica el elemento que más implicación tiene con la Dimensión de Gobernanza es la Ribera Lacustre y el que menos el Ecosistema. Para la Dimensión Antropológica el elemento que más implicación tiene con la Dimensión de Gobernanza es la configuración UrbanaRural y el que menos Paisajes. Finalmente en la Dimensión Económica el elemento que más implicación tiene con la Dimensión de Gobernanza es la Urbanización y en segundo lugar compartido por el resto de las Actividades Extractivas, Productivas y Terciarias. Es importante destacar además que los elementos de la Matriz de Actividades (Extractivas, Productivas, Terciarias y de Conectividad) son los que en mayor medida se han visto regulados o implicados con la Dimensión de Gobernanza en sus cuatro características.

\section{CARTOGRAFÍAS SOCIOTEMPORALES DEL ESPACIO LACUSTRE}

El Espacio Lacustre del Llanquihue ha sido configurado por la sucesión de tres periodos históricos o etapas de 50 años como escala significativa y coyuntural en la evolución y tendencias de su organización territorial.

ETAPA 1: 1850 - 1900: Entre la colonización y el establecimiento de poblaciones alrededor del lago.

En la Dimensión Ecológica se aprecia la importancia del ecosistema virgen, con 1.600 $\mathrm{km} 2$ de superficie cuenca lacustre con suelos de roca volcánica y un clima templado lluvioso con alrededor de $2.000 \mathrm{~mm} / \mathrm{año}$ de precipitaciones. El lago tiene una superficie de $860 \mathrm{~km}^{2}$ y un único desagüe, el río Maullín de $85 \mathrm{Km}$ de largo hasta desembocar al Océano Pacífico (DGA MOP 2004).

En la Dimensión Antropológica se cuenta con el Censo 1865: 1750 colonos y un 88\% de población rural en la cuenca del lago. La colonia es familiar de tradición alemana con un $80 \%$ de profesionales (Weil, J. 2002). El territorio de la colonia es disperso rural y aislado aproximadamente $523 \mathrm{~km}^{2}$ ocupados en un paisaje virgen de bosques impenetrables, imponente y extenso lago bajo dos volcanes.

En la Dimensión Económica destaca la extracción de maderas nativas, la producción agro-ganadera, incipientes casas comerciales, molinos, destilerías y curtiembres, pensado por el inmigrante para el autoabastecimiento de mercado interno y local a través de una navegación lacustre que es subvencionada y privada.

En la Dimensión de Gobernanza en el año 1853 se establece por ley el Territorio de Colonización Llanquihue, se entregan 100 cuadras por colono, hijuelas de 5x20 (app.150há). Ya en el año 1864 se promulgan leyes para concesiones a la navegación privada. Y en cuanto a la asociatividad se funda el Club Alemán en Frutillar (1882) y el de Puerto Varas (1888).

Diversos elementos configuran y determinan la cartografía de la Etapa 1: 1850 - 1900 (Fig. 08):

- Base: Red hidrográfica (ríos y esteros) con presencia imponente de los volcanes Osorno y Calbuco. Bosque nativo despoblado con extensas áreas erosionadas por las erupciones volcánicas. Se ha dibujado el límite de la cuenca hidrográfica y el desagüe del río Maullín. 
- Comunicaciones terrestres: principalmente a caballo por caminos estacionales, por el norte desde -Osorno-Valdivia con el llamado Camino de los alemanes y por el sur se accede desde Puerto Montt por el Camino de los alerces.

- Navegación lacustre: en desarrollo y expansión, transporte de pasajeros y carga. Sistema de pequeños muelles de intercambio comercial.

- Organización del territorio: mosaico de hijuelas o chacras y años de entrega a los colonos alemanes. Red de pequeños caseríos de borde lago con muelles de carga y descarga, villas principales en las cabecera norte y sur del lago coincidiendo con el acceso a los caminos importantes.

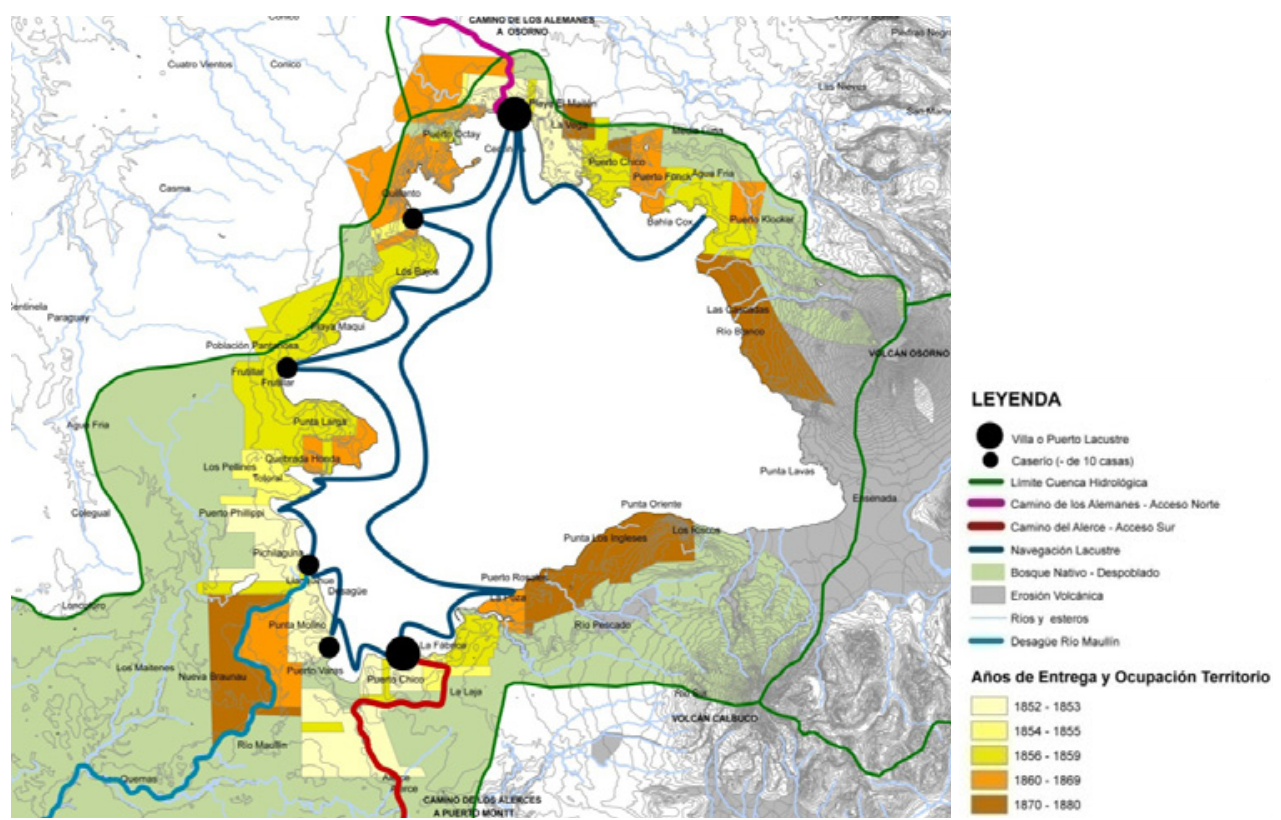

Fuente: La Organización del Espacio Lacustre, desde la superación del planeamiento sectorial (Castillo, 2010).

ETAPA 2: 1900 - 1950: Entre la consolidación del poblamiento, el auge lacustre y la conexión nacional con el transporte ferroviario.

En la Dimensión Ecológica se caracteriza el lago como oligotrófico de origen glaciar, con una lenta tasa de renovación de sus aguas (c/70 años). Se conocen las alturas de los volcanes 2.652msm. Volcán Osorno / 2.003msm. Volcán Calbuco, valorando las diversa flora, fauna e ictofauna (acuática) nativa. Se siembran las fértiles praderas agrícolas y se explota el bosque nativo. 


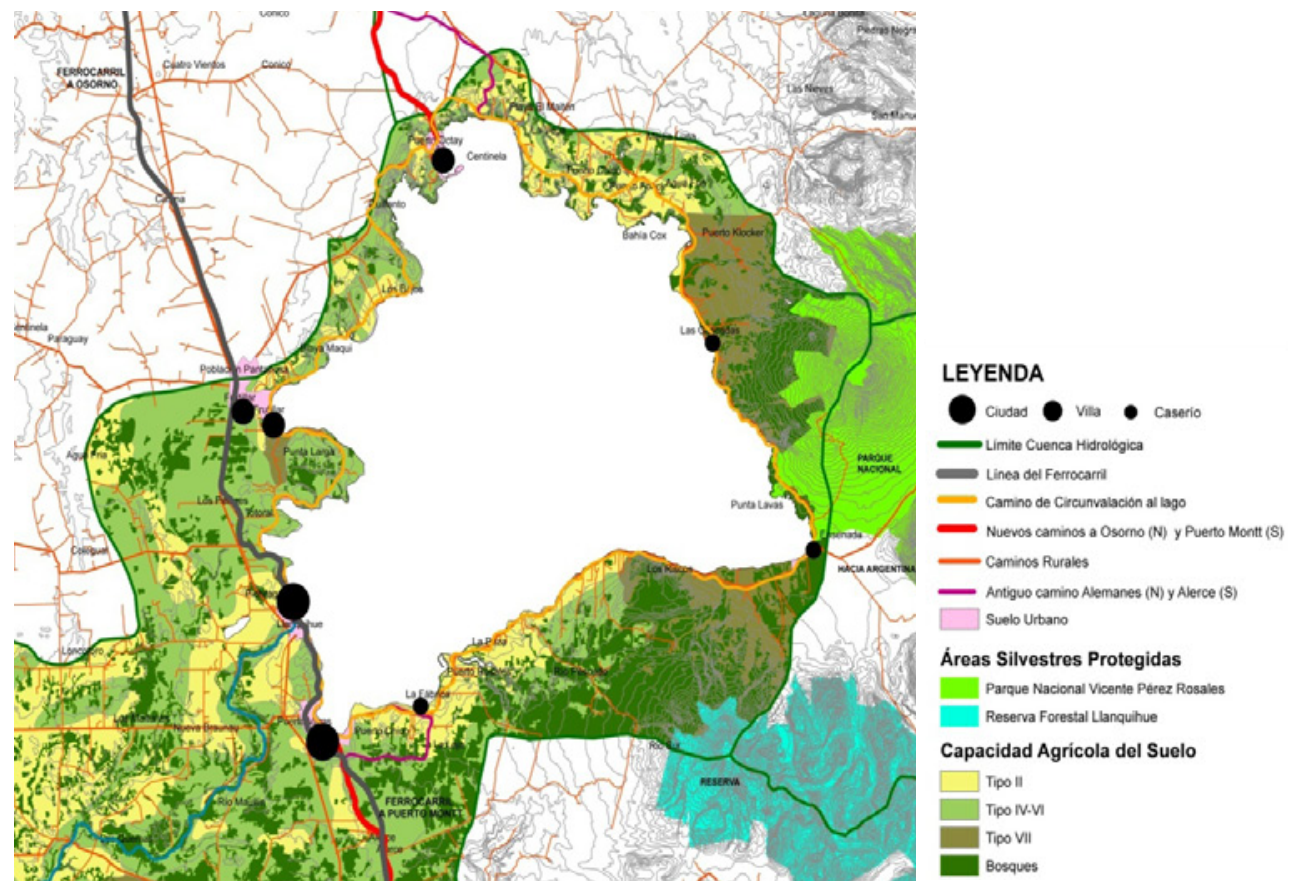

Fuente: La Organización del Espacio Lacustre, desde la superación del planeamiento sectorial (Castillo, 2010).

En la Dimensión Antropológica se cuenta con el Censo de 1930, la comuna de Rio Negro tiene 23605 habitantes (tramo norte del lago Llanquihue perteneciente a la Provincia de Osorno). La comuna de Puerto Varas (tramo sur del lago y que pertenece a la Provincia de Llanquihue, que incluye a Puerto Montt) tiene 21925 habitantes. Se estima un 86\% de población rural en la cuenca lacustre (Weil, 2002). El paisaje es predominantemente rural agrario con algunas villas y caseríos de clara influencia germana. Se construyen escuelas e iglesias alemanas, incluso se cuenta con un periódico en alemán distribuido localmente por el lago y a nivel nacional a través de la nueva red de ferrocarriles.

En la Dimensión Económica destaca la creciente industria agropecuaria y maderera con la creación de Ferias Ganaderas. En el año 1914, se conecta el territorio lacustre a la Red nacional de Ferrocarriles del Estado completando su integración al mercado nacional y a la banca local y nacional. A su vez se impulsa el turismo de descanso promovido por el Estado.

En la Dimensión de Gobernanza se declaran Áreas Protegidas en 1912 Reserva Llanquihue y 1926 el Parque Nacional Vicente Pérez Rosales. Se consolidan las sociedades y cooperativas agrícolas y ganaderas. Se reorganiza el territorio quedando la cuenca lacustre entre dos comunas Rio Negro y Puerto Varas. Se promulga la Ley de alcoholes en 1902 como un impuesto directo que afecta a la industria local. 
Diversos elementos configuran y determinan la cartografía de la Etapa 2, 1900-1950 (Fig. 09):

- Base: la capacidad agrícola del suelo, el tipo II es pradera agrícola y el tipo IV ñadis y humedales. Se destacan las áreas silvestres protegidas, Reserva Llanquihue y Parque Nacional Vicente Pérez Rosales.

- Comunicaciones terrestres: red de caminos rurales y nuevos trazados más expeditos para los caminos principales a Osorno (N) y Puerto Montt (S). Se completa el camino de circunvalación al lago. El trazado ferroviario por el lado oeste del lago cambia la tendencia de crecimiento de las ciudades lacustres.

- Navegación lacustre: se desestiman los pequeños muelles y dejando la actividad de pasajeros como oportunidad turística.

- Organización del territorio: en relación al trazado ferroviario y a los nuevos caminos rurales. Se traslada el peso de las ciudades hacia las que cuentan con estación ferroviaria y la dinámica lacustre se deteriora.

ETAPA 3: 1950 - 2000: Entre el decaimiento de los poblados de ribera hasta la tendencia de urbanización abusiva con la irrupción del transporte rodado, actividades económicas y turismo intensivo.

En la Dimensión Ecológica se comienzan a evidenciar las descargas de residuos urbanos e industriales sin tratar al lago, así como la deforestación y erosión del suelo agrícola en una urbanización creciente de la cuenca y la ribera (GWP-CEPAL 2003). Sumado a ello en el año 1960 se produce la erupción del Volcán Calbuco afectando al lago (lahares y lava) y a la cuenca lacustre (piroclastos y cenizas).

En la Dimensión Antropológica, el Censo 2002 señala para la comuna de Puerto Octay 10236 hab., Frutillar 15525, Llanquihue 16337 y Puerto Varas 32912 habitantes. El porcentaje de población rural en la cuenca alcanza sólo un 40\% (Weil, 2002). Se reconoce el patrimonio nacional de casonas alemanas y museos coloniales. Se desarrollan actividades identitarias: Semanas Musicales, Bierfest. Comienza a operar el Casino en Puerto Varas (1970). El paisaje se encuentra urbanizado, se evidencian los efectos del terremoto-erupción de 1960 y la decadencia del ferrocarril en favor de las autovías pavimentadas.

En la Dimensión Económica destaca la nueva industria acuícola situada en la ribera lacustre y con balsas de cultivo sobre el mismo lago, se desarrollan plantaciones madereras, industria láctea y agropecuaria. El turismo es estacional e internacional, masivo y de segunda residencia. Se ha entrado de lleno al mercado y banca internacional. La Ruta Panamericana N/S conecta el territorio con el resto del país, la ruta internacional E/O con Argentina y la ruta Interlagos con un mercado turístico de élite asociado a varias cuencas cercanas (CEC, 2007).

En la Dimensión de Gobernanza destaca 1974 con el proceso de regionalización que dividió el lago en dos provincias con cuatro comunas ribereñas. Las leyes territoriales del Plan Regulador Comunal (que sólo interviene dentro de los límites urbanos) y Plan Regulador Intercomunal de carácter más indicativo. La ley de división predios rústicos (1980) aceleró la urbanización de la cuenca en parcelas de agrado para segunda residencia. La asociatividad 
se expresa en el restringido Club de los 20(1954), la política Asociación de la Cuenca, ONG pro ecoturismo y acciones GTZ por la descontaminación del lago. En 2008 con la Estrategia Cuencas y las normas ambientales del lago se intenta empezar a registrar y acotar las problemáticas expresadas (CONAMA 2008).

Diversos elementos configuran y determinan la cartografía de la Etapa 3, 1950-2000 (Fig. 10):

- Base: tipos de uso del suelo y ZODUC Zonas de Desarrollo Condicionado propuestas por PRI. Se ha dibujado la batimetría del lago que evidencia las zonas bajas y más contaminadas. Y la división administrativa que fracciona el lago en 4 comunas.

- Comunicaciones terrestres: la red ferroviaria ha sido abandonada, las autovías ocupan el territorio Ruta Panamericana, Ruta Internacional - Argentina, Ruta Interlagos, Ruta de Circunvalación turística.

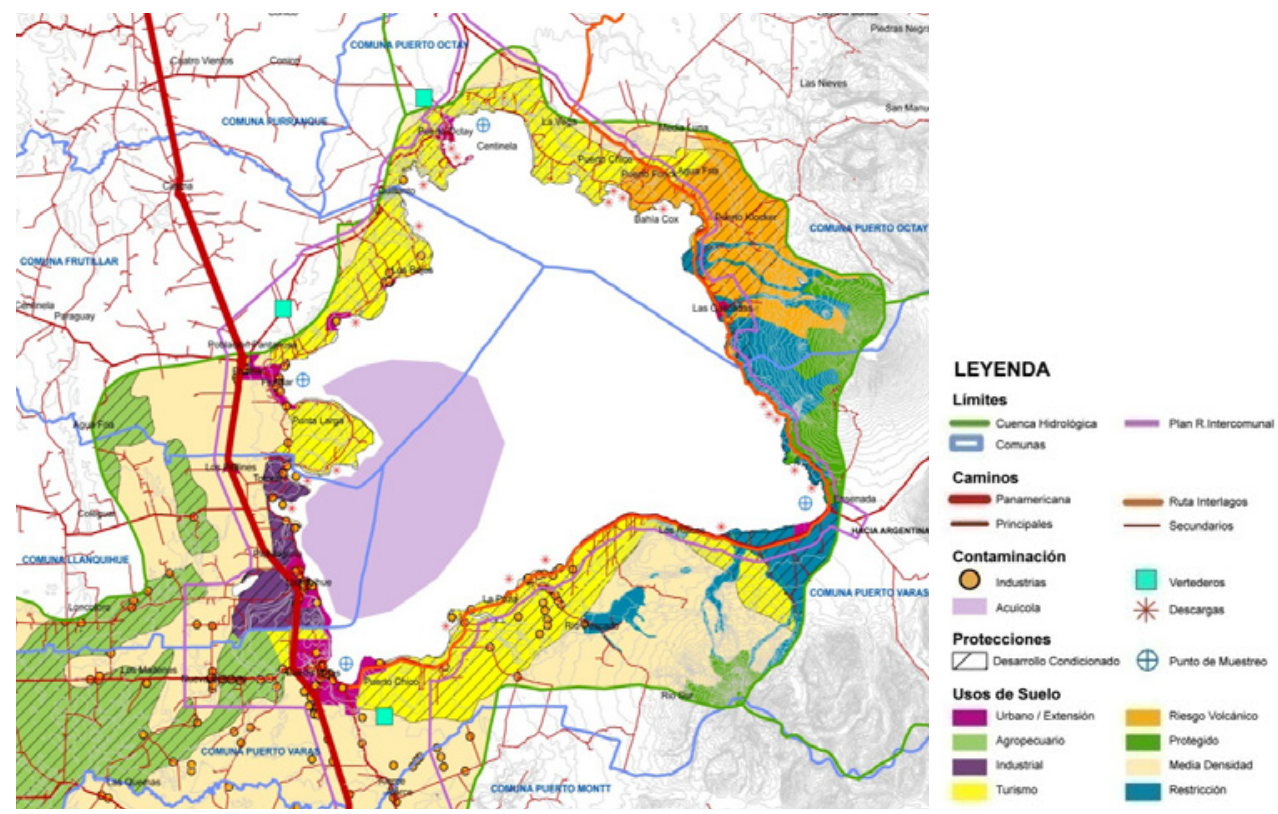

Fuente: La Organización del Espacio Lacustre, desde la superación del planeamiento sectorial (Castillo, 2010).

- Navegación lacustre: sólo deportiva y de recreo, ocio.

- Organización del territorio: Urbanización de la ribera lacustre, extensión urbana y segunda residencia en parcelas de agrado. Irrupción de puntos de contaminación por industrias, vertedero, acuicultura, descargas de residuos líquidos. Y afluentes contaminados. Se identifica la calidad de las aguas del lago en puntos oligotróficos, mesotróficos y eutróficos. 


\section{DISCUSIÓN Y ELEMENTOS DE REFLEXIÓN}

Un espacio singular como el Lacustre debe motivar la fusión sectorial, considerando el límite ambiental y la repercusión de los usos y actividades en la cuenca (Barragán, 1993). Si bien desde el punto de vista urbano y territorial ya se ha planificado en Chile; en el Espacio Lacustre se evidencia la falta de una coordinación sectorial-espacial entre la ordenación del territorio urbano y rural (CEPAL 1988). La gestión de los recursos hídricos, el manejo de áreas litorales, el manejo de cuencas o la evaluación de impacto ambiental son herramientas con una interesante vocación planificadora pero que no han sido lo suficientemente relacionadas o integradas en una visión de cuenca ecosistémica (Rees, 1996), con el conjunto de las cuatro dimensiones que plantea el concepto de Espacio Lacustre.

Se plantea un modelo de articulación de las distintas dimensiones que afectan al espacio, desde su base geográfica y ambiental a las estructuras urbanas y económicas que sobre él se asientan, teniendo en cuenta la dimensión social que construye y ocupa el espacio. Se diseña un modelo relacional - matricial de estas dimensiones que permite su aplicación en otros espacios semejantes (expresando sus variaciones coyunturales). Se trata de un modelo flexible en el que la evaluación de las relaciones entre las distintas dimensiones y áreas debe ajustarse a las circunstancias de cada caso de estudio. Al aplicar esta aproximación al caso del lago Llanquihue de la región de Los Lagos de Chile, se ha comprobado la utilidad del modelo propuesto.

Cabe señalar la demanda de una revisión en la concepción de herramientas de planificación en Chile, la falta de una visión global en la planificación tradicional, de integralidad en sus enfoques, así como la ausencia de mecanismos de participación efectiva de las comunidades en la concreción de sus herramientas, ha generado en muchos casos, planes desconectados de la realidad, con pocas probabilidades de incorporarse en la gestión urbana, imposibilitada de observar el fenómeno social cultural y económico que se lleva a cabo en el territorio durante el proceso de construcción de un Espacio Lacustre (Castillo, 2010).

El trabajo ha desarrollado una descripción de este espacio singular y su valor esencial, llegando a señalar unas relaciones fundamentales para su planificación. En un intento de hacer confluir las ideas emergentes con las ideas oficiales, cuyo origen se encuentra tanto en el planeamiento sectorial como en el urbano-territorial y con la información que desde otras disciplinas cercanas y/o desde las organizaciones civiles se está planteando; esta investigación puede ayudar a proponer un planeamiento coordinado y aplicado al Espacio Lacustre, visualizando los errores o carencias encontradas en su ordenación y abriendo la mirada a una manera no lineal para la optimización de un planeamiento no tradicional, más integral. Por lo tanto las conclusiones nos remiten a organizar respuestas transversales que articulen las distintas variables en cartografías geo referenciadas, para visualizar la interacción hídrica y disponer de criterios sólidos de la capacidad real de organización de un Espacio Lacustre. El Espacio Lacustre, como una oportunidad para una acción coordinada del planeamiento intersectorial.

Esta investigación avanza en la interpretación de un Espacio Lacustre a través de un punto de vista más amplio que específico, promoviendo la adopción de políticas e instrumentos de planeamiento integral que enfrenten el deterioro actual de los ecosistemas y consideren las cuatro dimensiones de un Espacio Lacustre. En este frágil paisaje cultural, el uso coordinado de los recursos naturales puede garantizar el bienestar de las comunidades residentes y la economía de las generaciones futuras (ILEC 2006). 
La necesidad de una propuesta de relaciones transversales en los ámbitos información, interacción y ordenación reconoce la importancia de estudiar el Espacio Lacustre a una escala ecosistémica, territorial y acotada para los instrumentos de planeamiento con una metodología de aproximación territorial que entienda el Espacio Lacustre como un nuevo concepto integrador de su organización. Se ha señalado interacción compleja de diferentes instrumentos de planificación indicativos, normativos, sectoriales y ambientales en un territorio acotado. La disparidad de los antecedentes oficiales e indicadores publicados y un limitado levantamiento de la información sectorial pública.

Con las cartografías elaboradas en cada una de las tres etapas se describe la dinámica coyuntural del Espacio Lacustre del Llanquihue y esta visualización socio temporal sumada a las matrices de análisis diseñadas y desarrolladas previamente, funda la necesidad de una optimización para la ordenación y organización del Espacio Lacustre, reconociendo las relaciones dinámicas de sus cuatro dimensiones en cuanto a la información, su interacción y su ordenación específica. Es un necesario ejercicio de síntesis proyectado sobre un Espacio Lacustre específico, en el que convendría seguir levantando casos de estudio. Se ha desarrollado el concepto de Espacio Lacustre como superación de las visiones sectoriales con las que se enfrenta la gestión y conservación de los entornos de los lagos.

La construcción del Espacio Lacustre requiere del planeamiento urbano y territorial que en estos momentos se manifiesta en una parcialidad que ha permitido el desarrollo del planeamiento sectorial, con sus injerencias directas e indirectas sobre el Espacio Lacustre. Un espacio específico como el Espacio Lacustre debe motivar la fusión sectorial, considerando el límite ambiental y la repercusión de los usos y actividades. Si bien desde el punto de vista urbano y territorial se ha planificado mucho, en el Espacio Lacustre se evidencia la falta de una coordinación espacial entre la ordenación del territorio urbano y rural. La gestión de los recursos hídricos, el manejo de áreas litorales, el manejo de cuencas o la evaluación de impacto ambiental son herramientas con una interesante vocación planificadora pero que no han sido lo suficientemente relacionadas o integradas en una visión ecosistémica o del conjunto de las cuatro dimensiones que plantea el concepto de Espacio Lacustre.

Por lo tanto la discusión y los elementos de reflexión nos conducen a la necesidad de una optimización e integración del planeamiento de un Espacio Lacustre, reconociendo las relaciones dinámicas y espaciales de sus cuatro dimensiones. Asimismo las conclusiones nos remiten a organizar respuestas transversales que articulen las distintas dimensiones del Espacio Lacustre, para representar en el tiempo la interacción biofísica, antropológica, económica y de gobernanza. De esta visualización se deben extraer los criterios para la comprensión compleja del Espacio Lacustre, señalando las divergencias de su construcción socio temporal y abriendo la mirada a una manera no lineal para la optimización de un planeamiento más sostenible.

\section{BIBLIOGRAFÍA}

BARRAGÁN, J.M. (1993): Ordenación planificación y gestión del espacio litoral. Barcelona. Oikos Tau.

CASTELLS, M. (1998): La sociología urbana en la sociedad de redes: de regreso al futuro. Conferencia Community and Urban Sociology Section American Sociological Association, San Francisco, Barry Wellman. 
CASTILLO, C. (2010): La organización del espacio lacustre: desde la superación del planeamiento sectorial. Tesis Doctoral, E.T.S. Arquitectura Universidad Politécnica de Madrid, España 2010.

CEC Ltda. (2007): Plan Regulador Intercomunal Ribera Lago Llanquihue e Hinterland Puerto Montt. Etapa III Proyecto - Ordenanza. Secretaría Regional Ministerial de Vivienda y Urbanismo de la X Región Chile.

CEPAL (1988): Gestión para el desarrollo de Cuencas de Alta Montaña en la Zona Andina. Naciones Unidas. Santiago de Chile.

CHILEAMBIENTE (2005): Estudio De Zonificación Preliminar Lago Llanquihue Corporación Chile Ambiente Santiago Chile.

CONAMA (2008): Anteproyecto de Normas Secundarias de calidad ambiental para la Protección de las Aguas del Lago Llanquihue Resolución Exenta № 4275, 03 de Noviembre de 2008, Publicado Diario Oficial 15 de Noviembre, 2008. Dirección Ejecutiva CONAMA, Chile.

DEL CASTILLO, M. (2009): La Huella Construida de la Oportunidad. CIUR, Cuadernos de Investigación Urbanística, Monográfico Desarrollo, Ciudad y Sostenibilidad, 67, 33-48. Madrid: Instituto Juan de Herrera.

DOUREJEANNI, A. y JOURAVLEV, A. (2001): Crisis de gobernabilidad en la gestión del agua. Ed. Naciones Unidas CEPAL. Santiago de Chile.

FARIÑA, J. e HIGUERAS, E. (1999): Turismo y uso sostenible del territorio, CIUR Cuadernos de Investigación Urbanística $n^{\circ} 28$, DUyOT, ETSAM, Madrid.

FOLCH, R. (2003): El territorio como sistema. Conceptos y herramientas de ordenación. Colección Territorio y gobierno: Visiones. Ediciones. D. de Barcelona.

GARNIER, J. (1976): Planificación Urbana y Neocapitalismo. Cuadernos críticos de Geografía Urbana Universidad de Barcelona.

GEDDES, P. (1973): La Sección Del Valle, en Lewis, D. “La ciudad: problemas de diseño y estructura". Gustavo Gili. Barcelona.

DGA MOP Gobierno de Chile (2004): Mapa Hidrogeológico de Chile Diagnostico y Clasificación de cursos y cuerpos de agua Cuenca Rio Maullin. Cade Idepe C. Ingenieria Santiago.

GWP-CEPAL (2003): Gobernabilidad efectiva del agua: Acciones a través de asociaciones en Suramérica. Naciones Unidas. Santiago de Chile.

ILEC (2006): Experiencia y Lecciones Aprendidas Lago Constanza .Lake Constance Experience and Lessons Learned Brief. Marion Hammerl, Lake Constance Foundation, Konstanz, Germany. Udo Gattenloehner, Global Nature Fund, Radolfzell, Germany.

LEFEBVRE, H. (1970): La révolution urbaine Paris: Gallimard, Collection Idées. Traducción: La Revolución Urbana; Madrid: Alianza Editorial, 1972.

LINDÓN, A. (2003): La miseria y la riqueza de la vida cotidiana en la ciudad: el pensamiento de Lefebvre. Revista Litorales. Año 2, n³, Departamento de Sociología, UAMIztapalapa, México y Sistema Nacional de Investigadores.

MCHARG, I. (1969): Design with Nature Se cita la versión en castellano de 2000, Proyectar con la Naturaleza Gustavo Gili, Barcelona.

NAREDO, JM (2006): Raíces económicas del deterioro ecológico y social: más allá de los dogmas Madrid: Siglo XXI, ISBN 84-323-1245-2. 
REES, W. (1996): Criterios territoriales de sustentabilidad, Ecología Política 12.

VERDAGUER, C. (2002): Proyectar con la naturaleza, de Ian L. McHarg: La fundación del urbanismo ecológico Madrid (España), Boletín No20 Ciudades para un futuro más sostenible. Edita: Instituto Juan de Herrera. Av. Juan de Herrera 4. 28040 MADRID. ESPAÑA.

VOLKER, W. (2002): Biopolis Patrick Geddes and the City of Life. Massachusetts Institute of Technology.

WEIL, J. (2002): Frutillar pasado y presente. U Austral de Chile, Valdivia. ISBN 956-291604-9

WRI (2005): Evaluación de los Ecosistemas del Milenio. Los Ecosistemas y el Bienestar Humano: Humedales y Agua. Informe de Síntesis. World Resources Institute, Washington, DC.

ZOIDO, F. (2000): Diccionario de Geografía Urbana, Urbanismo y Ordenación del Territorio. Editorial Ariel. Barcelona.

\section{RECONOCIMIENTOS}

Los autores agradecen el apoyo proporcionado por la Escuela de Arquitectura de la Universidad Diego Portales de Chile y al Centro de Desarrollo Urbano Sustentable, CEDEUS de la Universidad Católica de Chile, proyecto CONICYT FONDAP 15110020. 